\title{
The Progression of Nephrogenic Metaplasia of the Urinary Bladder to Clear Cell Adenocarcinoma: A Case Report
}

\author{
Catharine A. Dhaliwal Paul W. Fineron \\ Department of Pathology, Western General Hospital, Edinburgh, UK
}

\section{Key Words \\ Nephrogenic metaplasia • Nephrogenic adenoma • Adenocarcinoma $\cdot$ Bladder}

\begin{abstract}
Nephrogenic metaplasia (or nephrogenic adenoma) and clear cell adenocarcinoma of the bladder are uncommon lesions that cause diagnostic dilemmas for pathologists due to their similar morphologic features. Nephrogenic metaplasia describes a lesion in the lower urinary tract that is composed of small tubules resembling renal medullary tubules. It has been suggested that nephrogenic metaplasia may progress to clear cell adenocarcinoma but this possibility is not widely accepted. We present a case of clear cell adenocarcinoma of the bladder arising from nephrogenic metaplasia and discuss the evidence behind the association of these two distinct rare lesions.

Copyright $\odot 2012$ S. Karger AG, Basel
\end{abstract}

\section{Case Report}

A 67-year-old gentleman presented with hematuria and proteinuria. He had a significant past medical history of renal calculi (treated by lithotripsy), right hemicolectomy for adenocarcinoma of the appendix, hypertension and diffuse pulmonary fibrosis for which he was taking daily prednisolone $(5 \mathrm{mg} / 10 \mathrm{mg}$ alternate days). Cystoscopic examination revealed a papillary lesion

\section{KARGER}

Fax +4161306 1234

E-Mail karger@karger.ch

www.karger.com
(C) 2012 S. Karger AG, Basel

$1015-9770 / 12 / 0062-0106 \$ 26.00 / 0$

Accessible online at:

www.karger.com/cur within a bladder diverticulum. Pathology confirmed nephrogenic metaplasia with foci of intestinal metaplasia (fig. 1). Immunohistochemistry for ki67 demonstrated a low proliferation index (< $10 \%$ ). At routine cystoscopy 2 years later, the patient had a further papillary lesion in the bladder diverticulum that was resected. Histology of this revealed florid nephrogenic metaplasia with foci of highly pleomorphic cytokeratin-postive epithelial cells containing copious clear cytoplasm. These cytologically atypical cells were invading the lamina propria (fig. 1). Surgical diverticulectomy was performed as the patient refused cystectomy. The resection specimen confirmed the presence of a clear cell adenocarcinoma arising in an area of pre-existing nephrogenic metaplasia (fig. 1). This was accompanied by prominent lymphovascular invasion. Immunohistochemistry for ki67 revealed a proliferation index of $50 \%$. Six months later, small nodules were noted in the residual bladder at cystoscopy. These corresponded to areas of atypical nephrogenic metaplasia with solid glandular appearance, abnormal mitotic activity, and focal CEA positivity and raised proliferation index. The patient deteriorated with development of widespread lymphadenopathy in cervical, axillary and inguinal lymph nodes. A fine needle aspirate from an inguinal node confirmed metastatic adenocarcinoma, from which he succumbed following chemotherapy. He had no clinical or radiological evidence of malignancy elsewhere.

\section{Discussion}

We present a rare case of clear cell adenocarcinoma arising in an area of nephrogenic metaplasia. This is an unusual case as the morphology of the nephrogenic metaplasia was seen to change over time with subsequent development of a clear cell adenocarcinoma. The distinction between nephrogenic metaplasia and clear cell ad- 


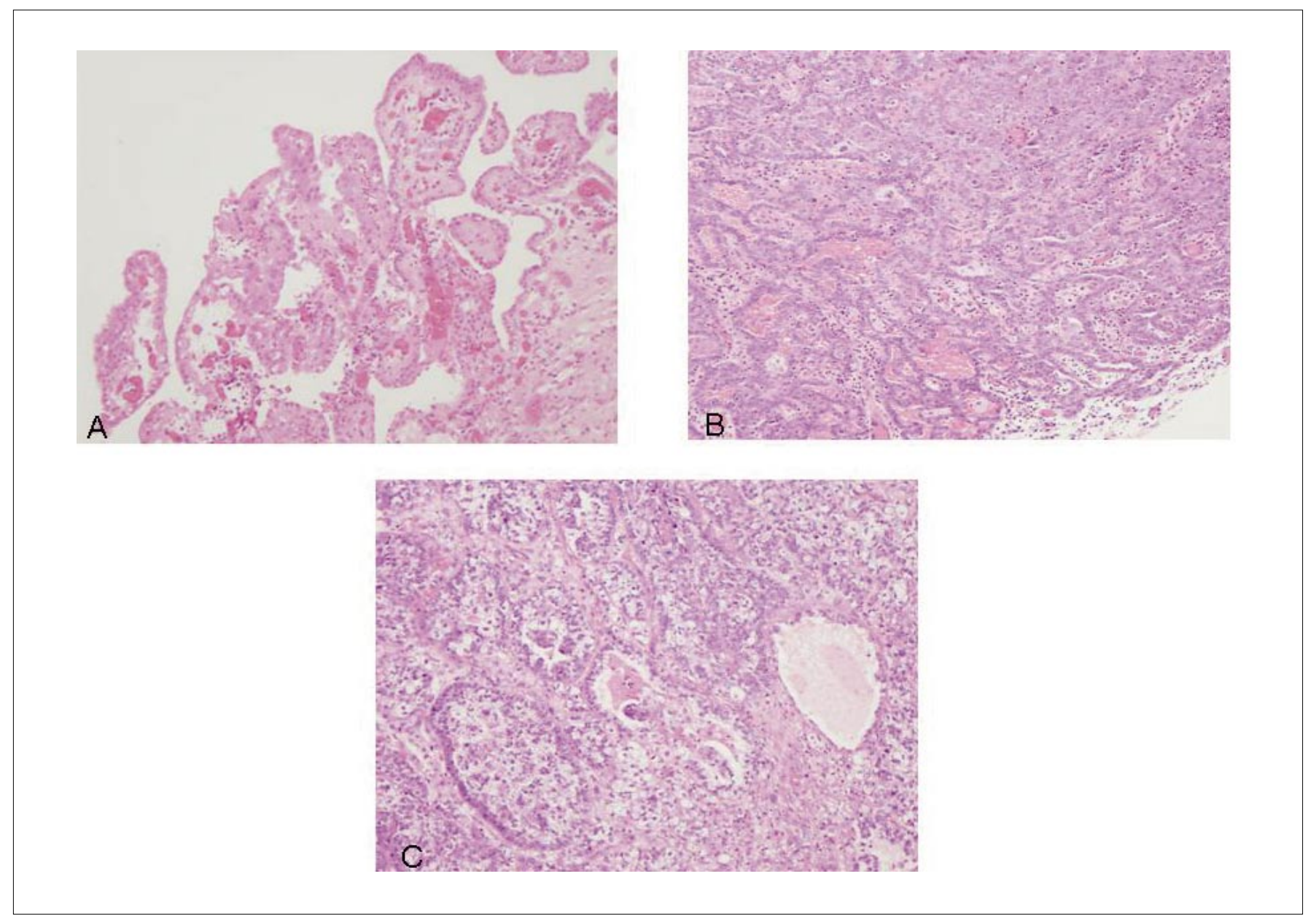

Fig. 1. A Nephrogenic metaplasia at first cystoscopy; B Florid nephrogenic metaplasia at follow-up cystoscopy; C Surgical diverticulectomy histology showing a clear cell adenocarcinoma arising in nephrogenic metaplasia with lymphovascular invasion.

enocarcinoma can be difficult and immunohistochemistry for ki67 has previously been reported to be useful in distinguishing between these diagnoses [1]. We support this finding as we found an initially low proliferation index $(<10 \%)$ in the typical nephrogenic metaplasia which subsequently increased in the florid atypical nephrogenic metaplasia and adenocarcinoma (approximately 50\%).

Glucocorticoids are widely used to treat chronic inflammatory conditions and our patient had been taking them daily for 3 years prior to presentation for treatment of pulmonary fibrosis. Use of these immunosuppressive drugs has been associated with an increased risk of cer- tain malignancies, predominately skin cancers and lymphomas [2]. There is also evidence that the incidence of bladder cancer may be elevated in patients taking oral glucocorticoids for inflammatory conditions [2]. The literature has mainly reported this association between glucocorticoids and urothelial carcinoma of the bladder as numbers have been too few to study the other bladder cancers. It does though still remain plausible that the daily use of prednisolone by our patient may have enhanced his risk of developing adenocarcinoma of the bladder.

There is continued debate about the histogenesis of clear cell adenocarcinoma and its association with neph- 
rogenic metaplasia. Cheng et al. [3] described 18 cases of atypical nephrogenic metaplasia characterised by marked cytologic atypia. They followed them up for a mean of 3.5 years and none developed carcinoma. They concluded that atypical nephrogenic metaplasia was a benign lesion and the cytological atypia was of no clinical significance. Tse et al. [4] followed-up 22 cases with nephrogenic metaplasia for less than 2 years with no reported malignant transformations. In contrast, our case showed a spectrum of morphological changes from nephrogenic metaplasia, atypical nephrogenic metaplasia to clear cell adenocarcinoma. We thus support a link between atypical nephrogenic metaplasia and clear cell adenocarcinoma.

Molecular evidence is also published supporting the association between nephrogenic metaplasia and clear cell adenocarcinoma. Tong et al. [5] studied the expression of PAX8 which is a cell lineage restricted transcription factor expressed in normal and neoplastic tissue of related origin. They found that PAX8 was detected in all nephrogenic metaplasia $(\mathrm{n}=35)$ and clear cell adeno- carcinomas $(n=7)$ of the lower urinary tract. It was not however expressed in normal urothelium, prostate adenocarcinoma, urothelial carcinoma, adenocarcinoma, or squamous cell carcinoma of the bladder. They went on to suggest that the expression of PAX8 in both nephrogenic metaplasia and clear cell carcinomas supported a related tissue origin of these lesions. Hartmann et al. [6] carried out comparative genomic hybridization analysis on a patient with multiple recurrences of nephrogenic metaplasia who subsequently developed clear cell adenocarcinoma. They reported a loss of heterozygosity at chromosomes 9 and 17 in clear cell adenocarcinoma and identical changes at chromosomes 1,4 and 8 in both the nephrogenic metaplasia and clear cell adenocarcinoma. Their results support a clonal evolution of nephrogenic metaplasia to clear cell adenocarcinoma.

We report a rare case of clear cell adenocarcinoma arising in florid nephrogenic metaplasia. Further comparative molecular and genetic studies will help define the relationship between these 2 distinct histological diagnoses.

\section{References}

$>1$ Gilcrease MZ, Delgado R, Vuitch F, Albores-Saavedra J: Clear cell adenocarcinoma and nephrogenic adenoma of the urethra and urinary bladder: a histopathologic and immunohistochemical comparison. Hum Pathol 1998;29:1451-1456.

$>2$ Dietrich K, Schned A, Fortuny J, Heaney J, Marsit C, Kelsey KT, Karagas MR: Glucocorticiod therapy and risk of bladder cancer. Br J Cancer 2009;101:1316-1320.
3 Cheng L, Cheville JC, Sebo TJ, Eble JN, Bostwick DG: Atypical nephrogenic metaplasia of the urinary tract: a precursor lesion? Cancer 2000;88:853-861.

$\checkmark 4$ Tse V, Khadra M, Eisinger D, Mitterdorfer A, Boulas J, Rogers J: Nephrogenic adenoma of the bladder in renal transplant and non-renal transplant patients: a review of 22 cases. Urology 1997;50:690-696.
$>5$ Tong G, Weeden EM, Hamele-Bena D, Huan Y, Unger P, Memeo L, O'Toole K: Expression of PAX8 in nephrogenic adenoma and clear cell adenocarcinoma of the lower urinary tract: evidence of related histogenesis? Am J Surg Pathol 2008;32:1380-1387.

6 Hartmann A, Junker K, Dietmaier W, Schröder S, Lopez D, Hofstädter F, Blaszyk $\mathrm{H}$ : Molecular evidence for progression of nephrogenic metaplasia of the urinary bladder to clear cell adenocarcinoma. Hum Pathol 2006;37:117-120. 